East African Medical Journal Vol. 85 No. 3 March 2008

FAMILY PLANNING AMONG HIV POSITIVE AND NEGATIVE CLIENTS IN A RESOURCE POOR SETTING IN SOUTH AFRICA

K. Peltzer, Human Sciences Research Council \& University of Limpopo. Li-Wei Chao, University of Pennsylvania, Olive Shisana, Human Sciences Research Council, P. Dana, Human Sciences Research Council and K. Zuma, Human Sciences Research Council, private bag x41, Pretoria 0001, South Africa

Request for Reprints to: Prof. K. Peltzer, Social Aspects of HIV / AIDS and Health, Human Sciences Research, Council, Private Bag X41, Pretoria 0001, South Africa

\title{
FAMILY PLANNING AMONG HIV POSITIVE AND NEGATIVE CLIENTS IN A RESOURCE POOR SETTING IN SOUTH AFRICA
}

\author{
K. PELTZER, LI-WEI CHAO, O. SHISANA, P. DANA and K. ZUMA
}

\begin{abstract}
Objective: To investigate family planning needs, knowledge of HIV transmission and HIV disclosure in a cohort sample that had undergone PMTCT in a resource poor setting.

Design. Cross-sectional survey.

Setting: Five clinics implementing PMTCT from Qaukeni Local Service Area, O.R. Tambo District in the Eastern Cape.

Subjects: The sample at postnatal care consisted of one postnatal interview $(\mathrm{n}=1310)$ when the infants were aged three months or less $(n=141,10.8 \%), 4-6$ months $(n=200$, $15.3 \%), 7-12$ months $(n=785,59.9 \%)$, or $13-18$ months ( $n=183,14.0 \%)$.

Results: One hundred and sixteen women were found HIV positive, $642 \mathrm{HIV}$ negative and 552 with unknown HIV status. Considering those with HIV test results, $15.3 \%$ were HIV positive. Almost four out of five women got counselling on safe sex during pregnancy but only two out of three women practiced safe sex during pregnancy. Postnatally, almost all women received counselling on family planning, yet use of contraceptives and condoms were low. HIV positive women used condoms more often than HIV negative women. HIV positive women were significantly more likely than HIV negative women to say that they did not intend to have more children. For HIV positive women PMTCT knowledge was a positive predictor for the intention to have a child, while age, having a partner, HIV disclosure to partner and number of children were not significant. Pregnancy desire did not differ between HIV positive and HIV negative women regarding marital status, having two or more live births and HIV disclosure.

Conclusion: High pregnancy desires, low contraceptive and condom use were found among HIV positive women. The incorporation of HIV prevention into promotion of contraceptives by family planning programmes and service providers needs to be improved.
\end{abstract}

\section{INTRODUCTION}

Relatively little is known or researched about the sexual and fertility desires of people with HIV, how they achieve their sexual and fertility goals, their contraceptive preferences and use, their HIV prevention knowledge desires and skills, whether their sexual and reproductive health (SRH) and family planning (FP) needs can be achieved with minimal risks to self and to others (including the sexual partner, the unborn foetus, and the new born baby) without resorting to expensive technologies such as sperm washing or in vitro fertilisation (I) that are normally unavailable in resource poor settings.

A few studies haveexamined the sexual desires of People Living with HIV (PWH). Most of these studies suggest that diminished sexual activity, if at all, was related more to psychological aspects of HIV rather than physical or endocrine effects from the disease or treatments. One study (2) found that the majority of women with HIV continued to be sexually active and that sexual activity was not related to HIV illness stage or functional status. Other studies have found psychosexual dysfunction among women with HIV (1-4), although these symptoms were mostly among a small portion of the women interviewed 
and were unrelated to antiretroviral therapies (ART). For instance, Siegel et al. (5) found that $30 \%$ of the women in their study experienced diminished pleasure on sex, diminished participation in sex, or diminished sense of sexual attractiveness. A study in Burkina Faso (6) revealed that only 3\% out of 306 women in the study sample were sexually inactive after learning of their HIV positive status. Because these studies are among women with HIV and the results are not compared to a matched sample of women without HIV, it is unclear whether any change in sexual activity, if any, found in these sample populations could be attributed to HIV or not. Risk factors associated with $\mathrm{PWH}^{\prime}$ 's pregnancy risk behaviour (mostly defined as not intending to get pregnant but also not using the condom or other forms of modern contraception including the $\mathrm{PWH}^{\prime} \mathrm{s}$ belief that HIV causes infertility, having multiple and steady partners, and wanting more children or wanting to replace a child that died from HIV (7). Therefore, while the determinants of pregnancy risk behaviour among PWH include many traditional risk factors associated with HIV risk behaviour, wanting additional children and gaining self-esteem from fertility also play important roles.

A qualitative study in South Africa (8) showed that being HIV positive did not remove reproductive desires; PWH continued to desire to have children. Fear of partner and infant infection, having had an HIV infected baby, and strong community disapproval against $\mathrm{PWH}$ becoming pregnant were factors deterring further reproductive desires. However, these factors were counteracted by a personal strong desire to experience parenthood, fear of social stigma against childlessness or having too-few-children in a pro-natalist society, and the sexual partner's expectations for fertility. Because unprotected sex carries risk of pregnancy and HIV transmission, most public health messages for HIV prevention have involved the use of the condom and a de facto message that discourage $\mathrm{PWH}$ from having additional children (9). Many studies around the world, in both developing and developed countries, have shown that despite the potential risk of HIV transmission between partners and to the child, fertility desires among PWH are strong $(6,10)$.

Contraceptive use in South Africa is among the highest in all the countries in Africa ravaged by the HIV epidemic. Over $61 \%$ of all sexually active women used some form of modern contraception in 1998 (11), although black Africans, those with no children, and those living in rural areas were statistically significantly less likely to use modern contraceptions (12). Shisana et al. (13) found in a nationally representative sample in South Africa whose contraceptive information was complete in the survey that HIV positive women were more likely to be dual users (using the condom plus one other method), were more likely to use the condom (counting those who were dual users), and were less likely to be users of only the pill or only the injection. Nevertheless, over $40 \%$ of women with HIV did not use any form of contraception (including the condom), and their contraceptive use rate was only slightly more than that in women without HIV (41\% vs. 47\%).

Preventing, unintended pregnancy among HlV-positive women is an effective approach to reducing paediatric HIV infection and vital to meeting HIV-positive women's sexual and reproductive health needs (14). Although contraceptive services for HlV-positive women is one of the four cornerstones of a comprehensive programme for prevention of mother-to-child transmission of HIV (PMTCT), a review of PMTCT programmes found that implementers have not prioritised family planning (15). While there is increasing awareness about the importance of family planning and HIV integration, data about family planning from PMTCT clients are lacking.

The aim of this study was to investigate family planning needs, knowled ge of HIV transmission and HIV disclosure in a cohort sample that had undergone PMTCT in a resource poor setting

\section{MATERIALS AND METHODS}

Sample and Procedure: From It October 2003 to $30^{\text {th }}$ April 2004, 1534 pregnant women were recruited at first antenatal care visit, with $61 \%$ from five clinics implementing PMTCT and 39\% from the five communities around the five clinic areas in the Quakeni Local Service Area (LSA), O.R. Tambo District, in the Eastern Cape Province, South Africa. Recruitment of pregnant women in the clinics was done by retired nurses (one per clinic) and recruitment of pregnant women in the respective five communities and follow-up was done by volunteer community workers (trained in PMTCT community mobilisation) from those communities. both retired nurses and volunteer community workers were trained by the research team in interview-administration of the questionnaire. The recruitment of pregnant women in the community utilised a community mobilisation of PMTCT approach. Volunteer community workers held PMTCT awareness meetings in public places and recruited pregnant women (inclusion criteria of not having attended antenatal care with the current pregnancy) by going from house to house in the respective communities.

The follow-up at postnatal care consisted of one postnatal interview $(n=1310)$ when the infants were aged three months or less $(\mathrm{n}=141,10.8 \%), 4-6$ months $(\mathrm{n}=200,15.3 \%), 7-12$ months $(\mathrm{n}=785,59.9 \%) 7$ or $13-18$ months $(n=183,14.0 \%)$, and checking of the clinic records for the same patient at five PMTCT clinic sites. 
The clinic records showed that 1140 mothers collected their HIV results and those of teh babies.

The study was approved by the Rhodes University Ethics Committee. The field workers obtained informed consent (by explaining the purpose of the study and obtaining a signature) from each pregnant woman willing to participate in the research. In addition her permission was sought to conduct a postnatal interview with her either at the clinic or at her home. Anonymity and confidentiality of these women were assured. No names and contact details appeared on the questionnaires. Codes and identifying information were kept in a separate locked up place. Participants were interviewed in IsiXhosa (the major language in the target area) by trained field workers using a semi structured questionnaire translated from English into IsiXhosa. The translation was checked by two external bilingual experts. For the postnatal study, structured interviews were conducted in IsiXhosa and were carried out from July 2005 to January 2006.

Measures: A questionnaire for the postnatal survey was developed from the literature $(16,17)$ including the following sections containing both closed and open-ended questions for: sociodemographic characteristics, exposure to PMTCT interventions, knowledge of HIV transmission, HIV status disclosure, family planning and fertility intentions.
Data analysis: Data analyses were undertaken using the Statistics Package for Social Sciences (SPSS version 14.0). The chi-square test was used in order to detect possible relations between groups and the Student t-test to analyse proportions. Regression analysis was used to identify predictors for fertility intentions. The level of significance was set at $\mathrm{P}<0.05$ (95\% confidence intervals).

Limitations: The rural PMTCT sites were purposefully chosen. Since they were not randomly selected, it is possible that these clinics may not be representative of other resource poor settings in South Africa.

\section{RESULTS}

HIV status of mother: From all women who could be followed-up, 116 were found HIV positive, $642 \mathrm{HIV}$ negative and 552 with unknown HIV status. Considering those with HIV test results, $15.3 \%$ were found to be HIV positive.

PMTCT and HIV knowledge: Participants were knowledgeable about HIV transmission from mother to child. However, a high proportion $(36.7 \%)$ incorrectly believed that if a woman was infected, transmission of the virus to her child would "always" occur; only $51 \%$ of HIV positive and $57 \%$ of HIV negative women have the correct response (sometimes transmission of HIV from the pregnant woman to the baby occurs) (Table I ).

Table 1

HIV knowledge (incorrect responses)

\begin{tabular}{lllllll}
\hline & $\begin{array}{l}\text { HIV positive } \\
\text { No. }(\%)\end{array}$ & $\begin{array}{l}\text { HIV negative } \\
\text { No. }(\%)\end{array}$ & $X^{2}$ & P-value \\
\hline $\begin{array}{l}\text { Pregnant women who are HIV positive } \\
\text { transmit HIV to their babies (sometimes) }\end{array}$ & 59 & 50.9 & 363 & 56.7 & 3.42 & 0.33 \\
$\begin{array}{l}\text { Can a HIV positive mother infect her } \\
\text { baby with HIV during pregnancy? }\end{array}$ & 103 & 88.8 & 459 & 71.7 & 18.04 & 0.00 \\
$\begin{array}{l}\text { Can a HIV positive mother infect her } \\
\text { baby with HIV during delivery? }\end{array}$ & 110 & 948 & 623 & 97.2 & 4.83 & 0.09 \\
$\begin{array}{l}\text { Can a HIV positive mother infect her } \\
\text { baby with HIV during breastfeeding? }\end{array}$ & 111 & 95.7 & 591 & 92.5 & 2.35 & 0.31 \\
& & & & & & \\
\hline
\end{tabular}


Disclosure of HIV testing: Two out of threeHIV positive women had shared their test results with somebody else, with the highest disclosure with partners and mothers (Table 2).

Table 2

Disclosure of HIV testing ( $n=l 16$ )

\begin{tabular}{lll}
\hline & No. & $(\%)$ \\
\hline Shared HIV results with someone & 69 & 59.5 \\
...with partner & 60 & 51.7 \\
...with mother & 24 & 20.7 \\
...with sister & 19 & 16.4 \\
...with friends & 2 & 1.7 \\
\hline
\end{tabular}

Male involvement: Few partners accompanied the pregnant women to ANC with $14.9 \%$ and $15.3 \%$ of HIV positive and HIV negative respectively reporting being accompanied by their partners to ANC respectively. Although less than $15 \%$ of the HIV positive women's partners attended ANC with the pregnant women, $45.0 \%$ of HIV positive women's partners saw a health worker together with the women either at ANC or in other clinical settings. HIV positive women were comfortable discussing condom use with partners to prevent pregnancy $(54.3 \%)$ and STls $(44.7 \%)$. Having the partner accompanying the pregnant woman to antenatal care was significantly associated with getting an HIV test and knowing the HIV status of the woman $\left(\mathrm{X}^{2}=\right.$ 30.53, $\mathrm{P}<0.001$ ).

Family planning: Almost four out of five women got counselling on safe sex during pregnancy but only two out of three women practiced safe sex during pregnancy, which did not differ by HIV status. Postnatal, almost all women received counselling on family planning. Half of the women used condoms, one out of three used hormonal injections and one out of five used the pill.HIV positive women used condoms more often than HIV negative women. Otherwise postpartum family planning use is similar for both HIV positive and HIV negative women. Intentions to use different major family planning methods were higher than the current practice (Table 3).

Table 3

Family planning and HIV status in percentage

\begin{tabular}{llllll}
\hline Family planning & $\begin{array}{l}\text { Age of infant } \\
\text { (months) }\end{array}$ & $\begin{array}{l}\text { HIV positive } \\
\text { (n=l16) }\end{array}$ & $\begin{array}{l}\text { HIV negative } \\
\text { (n=642) }\end{array}$ \\
& & No. $(\%)$ & No. & $(\%)$ \\
\hline Counsellor explained safe sex during pregnancy & & 87 & 76.3 & 507 & 85.2 \\
Practiced safe sex during pregnancy & & 73 & 65.8 & 367 & 62.3 \\
Health care provider discussed family planning & $7-12$ & 53 & 93.0 & 378 & 96.7 \\
& $13-18$ & 20 & 87.0 & 70 & 83.3 \\
Hormonal injections (currently) & $7-12$ & 21 & 36.2 & 134 & 34.2 \\
& $13-18$ & 11 & 50.0 & 48 & 57.1 \\
Hormonal injection (intention to use) & & 54 & 47.0 & 348 & 54.3 \\
Condom (currently) & $0-3$ & 4 & 33.3 & 30 & 47.6 \\
& $4-6$ & 13 & 56.5 & 56 & 54.9 \\
& $7-12$ & 32 & 55.2 & 173 & 44.2 \\
Condom (intention to use) & $13-18$ & 9 & 40.9 & 60 & 71.4 \\
Pill (currently) & & 85 & 73.3 & 426 & 66.5 \\
& $7-12$ & 8 & 13.8 & 114 & 29.1 \\
Pill (intention to use) & $13-18$ & 4 & 18.2 & 22 & 26.2 \\
\hline
\end{tabular}


Two out of five HIV positive women expressed the intention to have another child, while three out of five did not. HIV positive women were significantly more likely than HIV negative women to say that they did not intend to have more children (Table 4).

Pregnancy desire (defined as intention to have one or more children) did not differ between HIV positive and HIV negative women by marital status, by having two or more live birth or by HIV disclosure; it also did not differ between pregnancy intention among HIV positive women; however between pregnancy intention among HIV negative women higher pregnancy desires were associated with HIV disclosure to someone, having less than two or more children and not currently married or cohabiting (Table 5).

\section{Table 4}

Intention to have another child

\begin{tabular}{llllll}
\hline & $\begin{array}{l}\text { HIV positive (n=116) } \\
\text { No. }(\%)\end{array}$ & $\begin{array}{l}\text { HIV negative (n=642) } \\
\text { No. (\%) }\end{array}$ & $X^{2}$ \\
\hline Within 1 year & 5 & 4.3 & 22 & 3.4 & \\
Within 2-3 years & 6 & 5.2 & 48 & 7.5 & $9.54^{*}$ \\
After 3 years & 34 & 29.3 & 270 & 42.3 & \\
Not at all & 71 & 61.2 & 298 & 46.8 & $8.35^{* *}$ \\
Intention to have another child & 45 & 38.8 & 340 & 53.3 & \\
\hline
\end{tabular}

Table 5

Factors associated with pregnancy desire

\begin{tabular}{|c|c|c|c|c|c|c|c|c|c|c|}
\hline & \multicolumn{4}{|c|}{ Pregnancy desire } & \multirow{3}{*}{$\begin{array}{l}\text { Preg- } \\
\text { nancy } \\
\text { intention } \\
\text { No. (\%) }\end{array}$} & \multicolumn{2}{|c|}{$\mathrm{HIV}+(\mathrm{n}=116)$} & \multicolumn{2}{|c|}{ HIV $-(n=642)$} & \multirow{3}{*}{$\mathrm{X} 2$} \\
\hline & HIV+ & & HIV- & $\mathrm{X} 2$ & & $\begin{array}{l}\text { No preg- } \\
\text { nancy } \\
\text { intention }\end{array}$ & $\mathrm{X} 2$ & $\begin{array}{l}\text { Preg- } \\
\text { nancy } \\
\text { intention }\end{array}$ & $\begin{array}{l}\text { No preg- } \\
\text { nancy } \\
\text { intention }\end{array}$ & \\
\hline & No. & $(\%)$ & No. $(\%)$ & & & No. $(\%)$ & & No. $(\%)$ & No. $(\%)$ & \\
\hline $\begin{array}{l}\text { Currently in } \\
\text { relationship }\end{array}$ & 45 & 100 & $33499.1)$ & 0.40 & 45100 & 6794.4 & 2.63 & 33499.1 & 29098.6 & 0.32 \\
\hline $\begin{array}{l}\text { Currently married/ } \\
\text { cohaboration }\end{array}$ & 15 & 33.3 & 12135.9 & 0.12 & 1533.3 & $30 \quad 42.3$ & 0.92 & $121 \quad 35.9$ & 13343.8 & $5.18^{*}$ \\
\hline $\begin{array}{l}\text { Live birth two } \\
\text { and more }\end{array}$ & 25 & 55.6 & 19357.3 & 0.05 & 2555.6 & $\begin{array}{ll}46 & 64.8\end{array}$ & 0.99 & 19357.3 & 20167.9 & $7.59^{* *}$ \\
\hline $\begin{array}{l}\text { HIV disclosure } \\
\text { to partner }\end{array}$ & 23 & 52.3 & 22165.8 & 3.09 & 2352.3 & 52.1 & 0.00 & 22162.8 & 13137.2 & 2.36 \\
\hline $\begin{array}{l}\text { HIV disclosure } \\
\text { to someone }\end{array}$ & 26 & 70.3 & 22876.5 & 0.70 & 2670.3 & $43 \quad 72.9$ & 0.08 & 22884.4 & 15370.2 & $14.33^{* * *}$ \\
\hline
\end{tabular}

${ }^{* * *} \mathrm{P}<0.001 ;{ }^{* *} \mathrm{p}<0.01 ;{ }^{*} \mathrm{P}<0.0 .5$ 
Predictors of intention to have a child among HIV positive and negative women: For HIV positive women PMTCT knowledge was a positive predictor for the intention to have a child, while age, having a partner, HIV disclosure to partner and number of children were not significant, while for HIV negative women HIV disclosure to the partner and lower age of the mother were predictors for the intention to have a child, while having a partner. PMTCT knowledge and number of children were not significant (Table 6).

Predictors of modern contraceptives (other than condoms) and condom use among HIV positive and negative women

For HIV positive women HIV non-disclosure to the partner was the only predictor for contraceptive use, while no intention to have a child, age, having a partner, PMTCT knowledge and number of children were not significant, while for HIV negative women the intention not to have a child and older age were predictors for contraceptive use, while having a partner, number of children, HIV disclosure to partner, and PMTCT knowledge were not significant. For HIV positive women older age and HIV disclosure to the partner were predictors for condom use, while having a partner, number of children, PMTCT knowledge and the intention to have a child were not significant. For HIV negative women poor PMTCT knowledge, not having a partner and HIV non-disclosure to the partner were predictors of condom use, while age, number of children, and intention to have a child were not significant (Table 7).

\section{Table 6}

Predictors of intention to have a child among HIV positive and negative women

\begin{tabular}{lcccc}
\hline & $\begin{array}{c}\text { HIV positive } \\
\text { Beta }\end{array}$ & P-value & $\begin{array}{c}\text { HIV negative } \\
\text { Beta }\end{array}$ & P-value \\
\hline Age of mother & -0.20 & 0.17 & -3.13 & 0.001 \\
Having a partner & -0.10 & 0.30 & -1.19 & 0.23 \\
Number of live children & 0.03 & 0.82 & -1.79 & 0.07 \\
HIV disclosure to partner & 0.02 & 0.82 & 6.26 & 0.000 \\
PMTCT knowledge index & 0.26 & 0.005 & -0.30 & 0.76 \\
\hline
\end{tabular}

(based on 4 items)

adjusted $\mathrm{R}$ square $=0.08$ 1adjusted $\mathrm{R}$ square $=0.13$

\section{Table 7}

Predictors of current modern contraceptives and condom use

\begin{tabular}{|c|c|c|c|c|c|c|c|c|}
\hline & \multicolumn{4}{|c|}{$\begin{array}{l}\text { Current modern contraceptive } \\
\text { use (other than condoms) }\end{array}$} & \multicolumn{4}{|c|}{ Current condom use } \\
\hline & \multicolumn{2}{|c|}{ HIV positive } & \multicolumn{2}{|c|}{ HIV negative } & \multicolumn{2}{|c|}{ HIV positive } & \multicolumn{2}{|c|}{ HIV negative } \\
\hline & Beta & $\mathrm{P}$-value & Beta & $\mathrm{P}$-value & Beta & $\mathrm{P}$-value & Beta & P-value \\
\hline Age of mother & 0.17 & 0.26 & 0.15 & 0.02 & 0.38 & 0.01 & 0.02 & 0.81 \\
\hline Having a partner & 0.09 & 0.35 & -0.04 & 0.34 & -0.03 & 0.78 & -0.10 & 0.009 \\
\hline Number of live children & -0.15 & 0.32 & -0.09 & 0.16 & -0.22 & 0.14 & -0.04 & 0.54 \\
\hline HIV disclosure to partner & -0.21 & 0.03 & -0.01 & 0.79 & -0.19 & 0.03 & -0.09 & 0.03 \\
\hline $\begin{array}{l}\text { PMTCT knowledge index } \\
\text { (based on } 4 \text { items) }\end{array}$ & -0.07 & 0.47 & -0.01 & 0.85 & 0.18 & 0.06 & -0.14 & 0.001 \\
\hline Intention to have a child & 0.02 & 0.85 & -0.16 & 0.000 & 0.13 & 0.17 & -0.07 & 0.12 \\
\hline
\end{tabular}




\section{DISCUSSION}

From all women who could be followed-up, 116 were found HIV positive, 642 HIV negative and 552 with unknown HIV status. Considering those with HIV test results, $15.3 \%$ were found to be HIV positive, which is lower (above 20\%) than antenatal HIV positive rates from the study district (18) In our study, participants were knowledgeable about HIV transmission from mother to child. However, a high proportion $(36.7 \%)$ incorrectly believed that if a woman was infected, transmission of the virus to her child would "always" occur. This finding concurs with a study in the Western Cape (19).

Almost four in five women got counselling on safe sex during pregnancy but only two in three women practiced safe sex during pregnancy, which did not differ by HIV status. Postnatally, almost all women received counselling on family planning. Half of the women used condoms, one out of three hormonal injections and one out of five the pill. HIV positive women used more often condoms but not other forms of contraception than HIV negative women which conforms to a study among PMTCT primary care clients in urban slums in Nairobi (20). Nebie et al. (6) also found poor use of contraceptive methods despite regular advice and counselling. Pregnancy incidence among HIV positive women remained comparable with the pregnancy rate in the general population.

We also inquired about future childbearing desires and found that women with HIV were statistically significantly less likely to want additional children than those without HIV. However, 39\% of HIV positive women intended to have another child. Pregnancy desire (defined as intention to have one or more children) did not differ between HIV positive and HIV negative women regardless of marital status, by having two or more live birth and or by HIV disclosure; it also did not differ between pregnancy intentions among HIV positive women. Similarly, a study conducted at the HIV clinic of the Center for special Studies in Sagamu, Nigeria, showed that $63.3 \%$ of the participants had a desire to have children even though $50.4 \%$ already had two or more children (1). This finding about the respondent's futurefertility intention together with the finding that women with HIV had lower overall contraceptive use rate is somewhat worrisome. Although $90 \%$ of all women were counselled about family planning, we would have expected a higher condom use rate among women with HIV than women without HIV, and perhaps even a greater likelihood of using any form of contraception to prevent additional pregnancies given their lower future fertility intentions. Because we did not measure the actual content of the family planning counselling provided by the various providers, we are not able to provide plausible reasons for this finding. Using only women with HIV as a sub-sample, we tried to look for determinants of future fertility intentions.

The results from a logistic regression with "intention to have another child or not in the future" as the dependent variable showed that among the many explanatory variables included in the model, PMTCT knowledge was the only significant (and positive) explanatory variable, while age, having a partner, and number of children were not significant predictors of future fertility intentions. Further, for HIV positive women HIV non-disclosure to the partner was the only predictor for contraceptive use, while no intention to have a child, age, having a partner, PMTCT knowledge and number of children were not significant; and predictors for condom use included older age and HIV disclosure to the partner but not having a partner, number of children, PMTCT knowledge and the intention to have a child. This seems to suggest that higher knowledge of PMTCT led to higher fertility desires among women with HIV or higher fertility desire led to the acquisition of PMTCT knowledge. Worrisome results are that avoidance of pregnancy was not associated with contraceptive and condom use and HIV nondisclosure was a predictor for contraceptive use.

\section{CONCLUSION}

In conclussion, this study found high pregnancy desires among HIV positive women, and low contraceptive and condom use. The incorporation of HIV prevention into promotion of contraceptives by family planning programmes and service providers needs to be improved.

\section{ACKNOWLEDGEMENT}

This study was funded by the Ford Foundation.

\section{REFERENCES}

1. Gilling-Smith, C., Nicopoullos, J.D.M., Semprini, A.E. and Frodsham, L.C.G. HIV and reproductive care - a review of current practice. B.JOG 2006; 113:869-878.

2. Bova, C. and Durante, A. Sexual functioning among HlV-infected women. AIDS Pat. Ca. 2003; 17:75-83.

3. Keegall, A., Lambert, S. and Petrak, J. Sex and relationships for HIV-positive women since HAART: A qualitative study. AIDS Pat. Ca. 2005;19: 645-654.

4. Lambert, S., Keegan, A. and Petrak, J. Sex and relationships for HIV positive women since HAART: a quantitative study. Sex. Trans. Infect. 2005; 81: 333-337.

5. Siegel, K.. Schrimshaw, E.W. and Lekas H.-M. Diminished sexual activity, interest, and feelings of attractiveness among HIV-infected women in two eras of the AIDS epidemic. Arch. Sex. Be. 2006; 35:437-449. 
6. Nebie, Y., Meda, N., Leroy, V., et al. Sexual and reproductive life of women informed of their HIV seropositivity: a prospective cohort study in Burkina Faso. J. Acquir. Immune. Def. Syndr. 2001; 28: 367-372.

7. Van Benthem, B.H., de Vincenzi, I., Delmas, M.C., et al. Pregnancy before and after HIV diagnosis in European cohort HIV-infected women. European Study on the Natural History of HIV Infection in Women. JAIDS. 2000; 14:2171-2178.

8. Cooper, D., Harries, .I., Myer, L., Orner, P., Bracken, H "Life is still going on": Reproductive intentions among HIV-positive women and men in South Africa. Soc. Sci. EMed. 2007. doi: 10.1016/j.socscimed.2007.03.019

9 Kass, N.l. Policy, ethics and reproductive choice: Pregnancy and child-bearing among HIV-infected women. Act. Paediat. Suppl. 1994; 400:95-98.

10. Rutenberg, N., Biddlecom, A.E. and Kaona, A.D. Reproductive decision-making, in the context of HIV and AIDS: A qualitative study in Ndola, Zambia. Int. Fam. Plann. Persp. 2000; 26:124-130.

11. DHS. Contraception and Fertility Preferences. DHS South Africa Report Chapter 4. Pretoria: Department of Health, 1998.

12. Burgard, S. Factors associated with contraceptive use in late and post-apartheid. South Africa. Stud. Fam. Plann. 2004; 352: 91-103.

13. Shisana, O., Rehle, T., Simbayi, L.C., et al. South African national HIV prevalence, HIV incidence, behaviour and communication survey. Cape Town: HSRC Press, 2005.

14. World Health Organization WHO, United Nations Population Fund [UNFPA), Joint United Nations
Programme on HIV / AIDS (UNAIDS), International Planned Parenthood Federation (IPPF) (2005) Sexual and reproductive health and HIV / AIDS: a framework for priority linkages. Geneva, Switzerland, WHO, Oct. 2005. Available online at http://www.who.int/ reproductive-health/stis/docs/ framework_priority_linkages.pdf

15. Rutenberg, N. and Baek, C. Field experiences integrating family planning into programs to prevent mother-to-child transmission of HIV. Stud. Fam. Plann. 2005; 363:235-245.

16. Peltzer, K., Skinner, D., Mfecane, S., et al. Factors influencing the utilization of prevention of motherto-child-transmission (PMTCT) services by pregnant women in the Eastern Cape, South Africa. Health SA Gesondheid, 2005;101: 26-41.

17. Rutenberg, N., Baek, C., Kalibala S. and Rosen J. Evaluation of United Nations-supported pilot projects for the Prevention of Mother-To-Child Transmission of HIV. New York UNICEF, 2003.

18. Eastern Cape Department of Health. PMTCT quarterly statistics. Bisho: Department of Health 2006.

19. Ethiebet, M. A., Fransman, D., Forsyth, B., Coetzee, N. and Hussey, G. International prevention of mother to child HIV transmission into antenatal care: learning from the experiences of women in South Africa. AIDS Care. 2004; 161: 37-46.

20. Baek C. \& Rutenberg, N. Addressing the family planning needs of HIV-positive PMTCT clients: Baseline findings from an operations research study," Horizons Research Update. Washington, D.C.: Population Council, 2005. 